\title{
A variação lexical no campo semântico vestuário e acessórios: um estudo a partir dos dados do Projeto ALiB
}

\author{
The lexical variation in the semantic field clothing and accessories: \\ a study from data of ALiB Project
}

\author{
Marcela Moura Torres Paim* \\ Universidade Federal da Babia \\ Salvador, Bahia, Brasil
}

\begin{abstract}
Resumo: Este artigo objetiva investigar itens semântico-lexicais do campo vestuário e acessórios a partir dos inquéritos das localidades que integram a rede de pontos do Projeto ALiB, visualizando como a linguagem de indivíduos possui marcas linguísticas específicas que constroem, mantêm e projetam a sua identidade social de faixa etária através do léxico. O termo identidade está sendo aqui concebido, segundo Ochs (1993, p. 289), "como um termo que pode abranger uma gama de personae, não sendo, portanto, fixa nem categórica". O cenário da pesquisa é constituído por informantes estratificados por sexo, faixa etária e escolaridade. A análise do corpus possibilitou a descrição da diversidade lexical do português falado no Brasil, seguindo os princípios da Geolinguística Pluridimensional.
\end{abstract}

Palavras-chave: Língua portuguesa. Variação. Léxico. Dialetologia.

\begin{abstract}
This paper aims to investigate semantic-lexical items from the field of apparel and accessories from the surveys of the localities that integrate the ALiB Project's network of points, visualizing how the language of individuals has specific linguistic marks that build, maintain and project their social identity through the lexicon. The term identity is here conceived, according to Ochs (1993, p. 289), "as a term that can embrace a range of personae, and is therefore neither fixed nor categorical". The research scenario is made up of informants stratified by sex, age group and schooling. The analysis of the corpus made possible the description of the lexical diversity of the Portuguese spoken in Brazil, following the principles of Pluridimensional Geolinguistics.
\end{abstract}

Keywords: Portuguese language. Variation. Lexicon. Dialectology.

\section{INTRODUÇÃO}

O nível lexical da Língua Portuguesa tem sido objeto de estudo de muitas áreas da Linguística pelo fato de configurar uma das fundamentais estratégias utilizadas pelas pessoas, enquanto falantes/ouvintes, para expressar o mundo/espaço dito real. Por isso,

\footnotetext{
* Professora do Programa de Pós-Graduação em Língua e Cultura - PPGLinC - Universidade Federal da Babia, Salvador, Bahia, Brasil. E-mail: marcelamtpaim@yahoo.com.br.
} 
esse nível possui um importante papel no que se refere à variação, podendo-se, dessa forma, encontrar nesse contexto uma notável variedade regional e sociocultural do português, afinal os itens lexicais utilizados por habitantes de uma área geográfica determinada podem refletir o ambiente físico e social em que esses falantes estão inseridos.

O estudo da variação lexical pode ser realizado sob diferentes perspectivas, como, por exemplo, conforme o uso da língua do ponto de vista temporal, a diversidade diacrônica, segundo o uso num espaço geográfico determinado, evidenciando a parte diatópica, a variação de acordo com a faixa etária dos indivíduos, salientando a diageracionalidade, dentre outras possibilidades.

Este artigo, de cunho dialetológico, dedica-se à investigação lexical. É, portanto, nesse contexto de descrição da realidade linguística das capitais brasileiras que se examinará a variação semântico-lexical presente nas respostas às seguintes perguntas do Questionário Semântico-lexical que integra o Questionário Linguístico do Projeto Atlas Linguístico do Brasil (ALiB) - área semântica vestuário e acessórios:

188. Como se chama a peça do vestuário que serve para segurar os seios?

189. Como se chama a roupa que o homem usa debaixo da calça?

190. Como se chama a roupa que a mulher usa debaixo da saia?

191. Como se chama aquilo que as mulheres passam no rosto, nas bochechas, para ficarem mais rosadas?

192. Como se chama um objeto fino de metal, para prender o cabelo?

193. Como se chama o objeto de metal ou plástico que pega de um lado a outro da cabeça e serve para prender os cabelos? (COMITE NACIONAL DO ALiB, 2001, p. 37).

Com o intuito de refletir sobre a identidade social de faixa etária, foi utilizada a Teoria Social do Discurso, desenvolvida por Fairclough em Discurso e mudança social (2001). Segundo o referido autor, o discurso é um modo de ação, uma forma como as pessoas podem agir sobre o mundo e especialmente sobre os outros, como também uma maneira de representação, ou seja, é uma prática de significação do mundo, constituindo e construindo o mundo em significado. Tal prática evidencia, dentre os aspectos relativos aos efeitos construtivos, a construção, a manutenção e a projeção de identidades sociais. Dessa forma, pode-se perceber que o discurso é o local onde as identidades sociais são evidenciadas.

Embora não seja um tema preferencial para a área, as questões de identidade social têm sido investigadas também no âmbito dos estudos linguísticos. Com o objetivo de enfatizar o enfoque de identidade social adotado neste artigo, no que diz respeito a essas abordagens, foi utilizado como parâmetro o trabalho de Hoffnagel (1999), considerado como exemplar para este tema. Focalizando uma perspectiva de análise na sociolinguística interacional, Hoffnagel, (1999, p.81) comentando Ochs (1993, p. 289), explica que: 
[...] a identidade social é formada de uma gama de personae sociais que pode ser invocada ou atribuída ao longo da vida, não sendo, portanto, fixa nem categórica, pois um indivíduo pode evidenciar aspectos diferentes como faixa etária, sexo, profissão etc., dependendo de com quem se está interagindo [...] (HOFFNAGEL, 1999, p. 81)

Neste trabalho, será feito o estudo da identidade social de faixa etária na fala de informantes com base na utilização de itens lexicais, cujos dados foram obtidos por meio da aplicação das seis perguntas do Questionário Semântico-Lexical, relativas ao campo semântico vestuário e acessórios, considerando o repertório linguístico de informantes da faixa I (18-30 anos) e faixa II (50-65 anos).

$\mathrm{O}$ interesse nesta pesquisa decorre do fato de o léxico permitir observar a preservação de parte da memória sócio-histórica e linguístico-cultural que uma comunidade pode fazer do seu contexto, além de permitir a documentação da variação geolinguística do léxico do português falado no Brasil. Realizar este trabalho também vem a contribuir para o objetivo mais amplo do Projeto $\mathrm{ALiB}$, no que diz respeito à realização da descrição da realidade linguística do Brasil, no que se refere à língua portuguesa, enfocando a identificação das variações diatópicas e léxico-semânticas na perspectiva da geolinguística pluridimensional.

\section{O ESTUDO DA VARIAÇÃO DIAGERACIONAL POR MEIO DO LÉXICO}

A visão de mundo de um determinado grupo pode ser analisada a partir do estudo do repertório lexical de uma comunidade de fala que possibilita verificar aspectos da identidade dos falantes, como faixa etária, classe social, origem geográfica, cultura, valores, crenças, que podem ser construídos, mantidos e projetados, dependendo dos diferentes contextos comunicativos em que os indivíduos estejam inseridos.

O léxico de uma determinada língua se configura por meio do relacionamento entre sociedade e cultura, o que possibilita ampliar a acepção de um vocábulo em uma determinada região. Logo veem-se vocábulos que são usados com frequência, outros que caíram em desuso e, por fim, outros que vão entrando no repertório dos usuários da língua ao longo do tempo. Conforme Santos (2011, p. 3), os itens lexicais presentes nos atlas linguísticos, atlas semântico-lexicais e estudos geolinguísticos integram parte do repertório de uma dada comunidade e são realizados na interação entre os indivíduos envolvidos, num determinado evento comunicativo, em torno dos quais se organizam as referências de espaço e de tempo, de maneira explícita ou não.

Nesse sentido, o léxico possibilita observar a leitura que uma comunidade realiza de seu contexto e a preservação de parte da memória sócio-histórica e linguístico-cultural de um grupo. Em situações comunicativas, é possível perceber, na elaboração do texto falado, como os informantes procuram, constante e conscientemente, a realização de formulações precisas para que exista a compreensão mútua e para que se consigam os objetivos da comunicação. É justamente esse empenho que instala na enunciação mecanismos que evidenciam o trabalho da escolha lexical.

Na perspectiva da faixa etária, é possível afirmar, segundo Preti (1991, p. 75), que a linguagem dos indivíduos de idade mais avançada, em geral, possui traços específicos que 
podem ser visualizados nos âmbitos prosódico, sintático, léxico e, sobretudo, discursivo ou conversacional. É justamente nesses últimos campos - léxico, discursivo ou conversacional - que será evidenciado o estudo da variação diageracional através do léxico.

Como esclarece o referido autor, a linguagem desse grupo pode ser investigada sob três pontos de vista que se relacionam e não são estáticos: o de caráter cultural, o social e o psicológico individual. No ponto de vista de caráter cultural, há a ideia de que os idosos possuem um papel determinado na sociedade em que vivem, conforme a tradição cultural a que pertencem; na segunda perspectiva, a de caráter social, existe a visão de que a sociedade tem uma postura em relação aos idosos e, de acordo com ela, processam-se as relações sociais entre os idosos e os demais grupos etários; e por último, no aspecto psicológico individual, encontra-se a ideia de que uma pessoa é tão velha quanto imagina ser.

Segundo aborda Preti (1991, p. 102), a linguagem dos idosos pode conter interferência de ordem natural, psicofísica (maior lentidão das reações na comunicação ativa ou receptiva, os problemas de audição e memória), e de ordem sociocultural, como, por exemplo, a situação estigmatizada das pessoas mais velhas na sociedade contemporânea, o que lhes pode ocasionar um sentimento de insegurança manifestada em todos os contextos de sua vida e, muito particularmente, no seu discurso.

É possível mencionar que apesar de existirem algumas marcas lexicais de cunho temporal, na fala dos indivíduos de idades mais avançadas especialmente, nem por isso essa linguagem se tornou incompreensível aos mais jovens, afinal os próprios idosos se encarregam de criar mecanismos para explicar os arcaísmos, as expressões fora de uso, a gíria de seu tempo. E são essas estratégias que configuram precisamente as marcas mais expressivas da linguagem desse grupo social.

Por meio do léxico, em vocábulos, em formas de tratamento (um dos índices sociolinguísticos mais expressivos para evocar as relações sociais entre falante/ouvinte), em expressões (frases-feitas, provérbios, expressões que, muitas vezes, remontam à sua infância ou a épocas anteriores da sua vida que permanecem na memória) relacionadas com sua época, as informações sobre o passado podem transparecer constantemente no discurso das pessoas de idade mais avançada.

Nessa perspectiva, Cardoso (2017, p. 125) ressalta que a língua possui um relacionamento muito forte com a trajetória cultural da sociedade uma vez que registra as diferentes mudanças que aconteceram na comunidade e sobre as quais assim se expressa:

Nesse contexto de relação, digamos íntima, língua-sociedade, aflora a necessidade de descrever, sistematizar e definir os veios dessa parceria. E para desempenhar essa função nenhum ramo dos estudos da linguagem mais apropriado do que a Geografia Linguística ou Geolinguística, forma de denominar mais recente, mas com o mesmo objeto. (CARDOSO, 2017, p. 125)

Tal pensamento revela que o léxico de uma língua pode permitir visualizar o grau de desenvolvimento social de um povo, pois pode mostrar a quantidade e o tipo de conhecimentos que ele detém, por permitir refletir a sua vida sócio-econômico-cultural. 
De acordo com Paim (2015),

O léxico de uma língua é um instrumento de produção cultural e, ao mesmo tempo, seu reflexo, afinal ele constitui um espaço privilegiado do processo de produção, acumulação, reiteração, transformação dos sistemas de valores, visão de mundo, ideologia e práticas sociais e culturais de um grupo humano. (PAIM, 2015, p. 246)

Uma das maneiras de documentar o léxico é através das pesquisas geolinguísticas que têm como produtos finais os atlas linguísticos, os quais possibilitam mapear por meio de cartas linguísticas, que permitem uma comparação posterior de dados. No que diz respeito ao léxico, os estudos geolinguísticos realizam o registro das variantes semânticolexicais usadas para denominação de um conceito num espaço geográfico que pode mostrar influências socioculturais e históricas, evidenciando traços dos indivíduos que podem denotar a sua escolaridade, a região, o sexo e a faixa etária.

No intuito de realizar a valorização do seu tempo, ou de se mostrarem integrados na sociedade em que vivem, as pessoas mais velhas fazem a seleção do inusitado de suas narrativas em função das necessidades da interação comunicativa, levando em conta os próprios valores e os do ouvinte ou da audiência. Enfim, expõe Preti (1991) que, procurando, no arquivo da memória, fatos para exemplificarem suas ideias, os informantes de faixa etária mais avançada vão acumulando uma preciosa documentação da longa "viagem no tempo" a que costumam entregar-se durante a conversação, denunciando, também, através da utilização de itens lexicais, a sua identidade social de faixa etária.

\section{O CENÁRIO DA PESQUISA}

O universo da pesquisa é um recorte da rede de pontos do Projeto ALiB, um empreendimento de âmbito nacional, em desenvolvimento, que tem por meta a realização de um atlas geral nacional no que diz respeito à língua portuguesa, objetivo que permeia a atividade dialetal no Brasil, desde começo do século XX, e ganha destaque nesse final/começo de milênio, por meio da iniciativa de um grupo de pesquisadores do Instituto de Letras da Universidade Federal da Bahia e de outras universidades.

A ideia de construção de um atlas linguístico brasileiro remonta a 1952, quando se estabeleceu, através do Decreto 30.643, de 20 de março, como principal finalidade da Comissão de Filologia da Casa de Rui Barbosa a "elaboração do atlas linguístico do Brasil". No entanto as dificuldades de ordens diferenciadas fizeram com que os dialetólogos brasileiros iniciassem o trabalho de mapeamento linguístico do Brasil pela produção de atlas regionais.

No Seminário Nacional Caminhos e Perspectivas para a Geolinguística no Brasil, realizado em Salvador, na Universidade Federal da Bahia, em novembro de 1996, com a participação de dialetólogos brasileiros e do Diretor do ALiR (Atlas Linguistique Roman), Prof. Michel Contini (Genoble), a ideia do Atlas Linguístico do Brasil foi retomada. Nesse evento, foi criado um Comitê Nacional, integrado pelos autores dos cinco atlas linguísticos regionais já publicados e por um representante dos atlas em andamento. 
Foram eles: os Professores Suzana Alice Marcelino da Silva Cardoso (UFBA), que presidiu o Comitê, Jacyra Andrade Mota (UFBA), Maria do Socorro Silva de Aragão (UFPB), Mário Roberto Lobuglio Zágari (UFJF), Vanderci de Andrade Aguilera (UEL) e Walter Koch (UFRGS), representando os atlas em andamento ${ }^{1}$.

O Projeto ALiB fundamenta-se nos princípios gerais da Geolinguística contemporânea, ou pluridimensional, enfatizando a variação espacial ou diatópica, mas sem deixar de levar em consideração as implicações de natureza social que não se pode, no estudo da língua, deixar de considerar. Dessa forma, o referido projeto tem o intuito de descrever o português falado no Brasil conforme os dados coletados em 250 pontos, representativos de todas as regiões, e recolhidos, in loco, a 1.100 informantes, distribuídos equitativamente por duas faixas etárias — 18 a 30 anos e 50 a 65 anos -, pelos dois sexos e, nas capitais de Estado, em número de 25 (as capitais Palmas, Estado de Tocantins, e Brasília, Distrito Federal, se excluem por questões metodológicas em virtude de serem cidades recém-criadas), por dois níveis de escolaridade — fundamental e universitário , ficando os demais pontos da rede com apenas informantes do nível fundamental.

Ao se publicar, em 2014, o volume de cartas linguísticas, algumas considerações iniciais já podem ser feitas sobre a diversidade linguística brasileira. Nesse sentido, apresentam-se neste artigo, de forma ilustrativa, resultados que revelam a variação de usos relacionada ao fator faixa etária, no que diz respeito ao campo semântico vestuário e acessórios.

\section{O QUE REVELAM OS DADOS DO CAMPO SEMÂNTICO VESTUUÁRIO E ACESSÓRIOS NAS CAPITAIS DO PROJETO ALiB?}

Os dados aqui analisados foram fornecidos por 200 habitantes das 25 capitais que integram a rede de pontos do Projeto ALiB. Em cada capital, foram entrevistados oito informantes, sendo quatro com nível universitário completo e quatro com nível fundamental (completo e/ou incompleto), distribuídos igualmente por duas faixas etárias (18 a 30 anos e 50 a 65 anos), de ambos os sexos, nascidos e criados na localidade, com pais também nascidos na mesma região linguística.

Os itens semântico-lexicais coletados foram organizados de acordo com as perguntas analisadas do campo semântico vestuário e acessórios.

\footnotetext{
${ }^{1}$ Atualmente, o Comitê Nacional do Projeto ALiB é constituído de 13 (treze) membros assim estruturado: Diretora Presidente - Jacyra Andrade Mota (Universidade Federal da Bahia), Diretora Executiva - Silvana Soares Costa Ribeiro (Universidade Federal da Bahia), Diretores Científicos: Abdelhak Razky (Universidade Federal do Pará); Aparecida Negri Isquerdo (Universidade Federal de Mato Grosso do Sul); Conceição Maria de Araújo Ramos (Universidade Federal do Maranhão); Fabiane Cristina Altino (Universidade Estadual de Londrina); Felício Wessling Margotti (Universidade Federal de Santa Catarina); Marcela Moura Torres Paim (Universidade Federal da Bahia); Maria do Socorro Silva de Aragão (Universidade Federal da Paraíba/Federal do Ceará); Marilúcia Barros de Oliveira (Universidade Federal do Pará); Regiane Coelho Pereira Reis (Universidade Federal de Mato Grosso do Sul); Valter Romano (Universidade Federal de Lavras) e Vanderci de Andrade Aguilera (Universidade Estadual de Londrina).
} 


\subsection{SOBRE A PEÇA DP VESTUÁRIO QUE SERVE PARA SEGURAR OS SEIOS}

Como respostas ao QSL 188 "Como se chama a peça do vestuário que serve para segurar os seios?" (COMITÊ NACIONAL, 2001, p. 37), foram documentadas, para além da variante sutiã, as variantes corpete, califon, porta seio e goleiro.

É importante mencionar que, nos dados coletados pelo Projeto ALiB, a referência às denominações da peça do vestuário que serve para segurar os seios foram feitas com uma alusão temporal que denuncia a variação diageracional na língua, como pode ser observado nos exemplos:

Exemplo 1:

INQ.: - Como é que chama a peça do vestuário que serve para segurar os seios?

INF.: - Sutiã.

INQ.: - Chama por outro nome?

INF.: - Antigamente eu só chamava, meu pai ainda chamava porta-seio.

(Recife, Mulher, Faixa Etária 2, Nível Universitário)

No exemplo 1, visualiza-se que a identidade social de faixa etária constrói-se pela revelação de que no passado as pessoas utilizavam um item lexical diferente, caracterizado por porta-seio, vinculado a uma fase anterior de suas vidas. Dessa forma, a informante denuncia reconhecer que a seleção lexical para a peça que serve para segurar o seio é diferente conforme a faixa etária, pois cita pessoa de faixa etária mais avançada - pai como usuária de maneiras diferentes de se referir a esta peça do vestuário feminino, configurando o uso do sutia na atualidade e porta-seio como a variante de antigamente.

A variação diageracional, também, está presente com o uso do item corpete, como revela o exemplo a seguir:

Exemplo 2:

INQ.: - Como é que chama a peça do vestuário que serve pra segurar o peito? Essa peça aqui da mulher que serve pra segurar o peito.

INF.: - Ah esse aí é corpete, né? De primeiro a gente dizia que só usava corpete.

(Macapá, Mulher, Faixa Etária 2, Nível Fundamental)

Os trechos da entrevista sugerem que a identidade social de faixa etária constrói-se pela revelação de que no passado o informante reconhece um item lexical diferente, caracterizado por corpete, como mostra o exemplo, vinculado a uma fase anterior de sua vida.

\subsection{SOBRE A ROUPA QUE O HOMEM USA DEBAIXO DA CALÇA}

Para além da variante cueca, como respostas ao QSL 189 "Como se chama a roupa que o homem usa debaixo da calça?” (COMITÊ NACIONAL, 2001, p. 37), foram documentadas as variantes ceroula, samba canção, sunga e zorba. 
Nessa questão, a identidade social de faixa etária é revelada por meio do uso da denominação ceroula, como mostra o exemplo a seguir:

Exemplo 3:

INQ.: - Como é que chama a roupa que o homem usa debaixo da calça?

INF.: - Cueca (risos)

INQ.: - Algum outro nome?

INF.: - Antigamente tinha aquelas... é... chamava ceroula, né?

(Campo Grande, Mulher, Faixa Etária 2, Nível Fundamental)

Os contextos em que a variante ceroula esteve presente evidenciaram o trabalho de seleção lexical por meio de itens lexicais denunciadores da faixa etária do informante, revelando, no caso deste estudo, que a seleção entre as denominações está relacionada ao caráter diageracional.

\subsection{SOBRE A ROUPA QUE A MULHER USA DEBAIXO DA SAIA}

No que se refere às respostas ao QSL 190 "Como se chama a peça do vestuário que a mulher usa debaixo da saia?” (COMITÊ NACIONAL, 2001, p. 37), foram registradas, para além da variante calcinha, as denominações calçola(ão), calça(ão), biquíni, tanga(uinha), cangula e rabichola.

Assim como ocorreu com as demais perguntas relacionadas ao vestuário, nos dados documentados pelo Projeto $\mathrm{ALiB}$, as denominações da peça do vestuário que serve para usar debaixo da saia foram realizadas com uma alusão temporal que evidencia a identidade social de faixa etária por meio da variação diageracional na língua, como pode ser visualizado no exemplo 4:

Exemplo 4:

INQ.: - E como se chama a peça do vestuário que a mulher usa debaixo da saia ou o que nós usamos antes da calça?

INF.: - A calcinha.

INQ.: - Também tem outro nome? Pros nativos?

INF.: - Ah, não era calçola? Chamavam mais calçola, né? Calcinha é mais uma expressão mais recente. Era calcola.

INQ.: - E as meninas? $\mathrm{E}$ as meninas, quando vão comprar pedem calçola ou calcinha?

INF.: - Ah, as meninas pedem calcinha, pedem tanga, né? As meninas já pedem específico de acordo com o modelo que elas querem, né? Nunca vão pedir calçola, porque hoje as meninas veem calçola como a calça grande da senhora idosa (risos). Desse tamanhão, então eles dizem que é a calça da vovó (risos).

(Florianópolis, Mulher, Faixa Etária 2, Nível Universitário) 
No caso apresentado, o papel da memória é fundamental, pois as lembranças possibilitam a oposição das designações lexicais do passado (calçola) e do presente (calcinha e tanga) ou, ainda, demonstrando a consciência de que antigamente se falava de maneira diferente. Por meio dessa oposição e dessa consciência, há a revelação da identidade social conceituada por Hoffnagel (1999) como constituída por uma gama de personae sociais que pode ser invocada ou atribuída ao longo da vida, não sendo, portanto, fixa uma vez que um indivíduo pode evidenciar aspectos diferentes como faixa etária, sexo, profissão etc., dependendo de com quem se está interagindo.

Assim, o discurso se configura como uma forma de representação, pois é uma prática de significação do mundo, que focaliza a construção, a manutenção e a projeção da identidade social de faixa etária da informante, por meio da seleção lexical diageracional, revelando a noção de temporalidade em que o discurso foi produzido.

\subsection{SOBRE O QUE AS MULHERES PASSAM NO ROSTO, NAS BOCHECHAS, PARA FICAREM MAIS ROSADAS}

A questão 191 do questionário semântico-lexical (QSL) apresentou designações, nas capitais do Brasil, que foram agrupadas em três categorias, a saber: a) blush; b) ruge e c) carmim. No que se refere ao aspecto diageracional, a denominação carmim ocorreu apenas em duas capitais, uma informante de Campo Grande e uma do Rio de Janeiro, na fala de uma mulher da faixa etária 2, como é possível visualizar a seguir:

\section{Exemplo 5}

INQ.: - Aquilo que as mulheres passam no rosto, nas bochechas, pra ficarem mais rosadas?

INF.: - É... antigamente, falava carmim.

INQ.: - Carmim?

INF.: - Carmim... vou passar carmim pra ir na festa, a minha vó falava. Eu lembro.

INQ.: - Bem, bem vermelhinho?

INF.: - É, bem, o carmim era bem vermelhinho.

INQ.: - É.

INF.: - Ficava aquela maçã de rosto bem vermelhinha, tava bonita.

(Campo Grande, Mulher, Faixa 2, Nível Universitário)

Exemplo 6

INQ.: - Como se chama aquilo que as mulheres passam no rosto, nas bochechas, pra ficarem mais rosadas?

INF.: - Ah, no meu tempo, era carmim, né?

(Rio de Janeiro, Mulher, Faixa 2, Nível Fundamental)

A denominação carmim é sinalizada como uma variante diageracional, revelando a identidade social de faixa etária das informantes. Esse aspecto também ocorre com o item ruge, sinalizado no discurso da maioria dos informantes das capitais brasileiras como uma 
variante típica de pessoas mais velhas. A designação blush, por sua vez, é apontada como a maneira mais atual de falar, como demonstra o exemplo que segue:

Exemplo 7

INQ.:- O quê que as mulheres passam no rosto aqui para ficarem mais coradinhas? INF.: - Então, pode ser blush ou pode ser ruge.

INQ.: - Humhum. Qual que é o mais comum? Que você ouve?

INF.: - Então, outro dia eu tava falando isso, é... os dois, eu acho estranho ruge, eu acho que é mais antigo, que as pessoas mais antigas falam ruge, eu já acho que é mais comum blush.

INQ.: - E você fala o quê?

INF.: - Eu falo blush.

(Manaus, Mulher, Faixa Etária 1, Nível Universitário)

\subsection{SOBRE O OBJETO FINO DE METAL, PARA PRENDER O CABELO}

No que diz respeito às respostas ao QSL 192 "Como se chama o objeto fino de metal, para prender o cabelo?” (COMITÊ NACIONAL, 2001, p. 37), foram registradas, para além da variante grampo, as denominações biliro, friso, misse, ramona, invisivel e presilha.

Assim como ocorreu com as demais perguntas relacionadas a esse campo semântico, nos dados documentados pelo Projeto $\mathrm{ALiB}$, as denominações para esse objeto foram feitas revelando a identidade social de faixa etária, como mostra a variação diageracional na língua, no exemplo 8:

Exemplo 8:

INQ.: - Como se chama um objeto fino de metal para prender o cabelo?

INF.: - Eu chamava biliro por causa da minha mãe, mas hoje eu chamo grampo.

(Recife, Mulher, Faixa Etária 1, Nível Universitário)

Pelo discurso demonstrado, visualiza-se que a identidade social de faixa etária constrói-se pela revelação de que no passado as pessoas utilizavam um item lexical diferente, caracterizado por biliro, vinculado a uma fase anterior de sua vida. Assim, a informante denuncia reconhecer que a seleção lexical para o objeto fino de metal para prender o cabelo é diferente conforme a faixa etária, pois cita maneiras distintas de se referir a este acessório, configurando o uso de biliro como a variante de antigamente.

\subsection{SOBRE O OBJETO DE METAL OU PLÁSTICO QUE PEGA DE UM LADO A OUTRO DA CABEÇA E SERVE PARA PRENDER OS CABELOS}

Para além da variante tiara, como respostas ao QSL 193 "Como se chama o objeto de metal ou plástico que pega de um lado a outro da cabeça e serve para prender os cabelos?" (COMITÊ NACIONAL, 2001, p. 37), foram documentadas as variantes diadema, arco, travessa, atraca, gigolete e passadeira. 
É importante mencionar, nos dados coletados pelo Projeto ALiB, que a referência às denominações para o objeto de metal ou plástico que pega de um lado a outro da cabeça e serve para prender os cabelos são feitas com uma alusão temporal que denuncia a variação diageracional na língua, como pode ser observado no exemplo 9:

Exemplo 9:

INQ.: - E o objeto de metal ou plástico que pega um lado a outro da cabeça?

INF.: - Tiara.

INQ.: - Que serve pra prender o cabelo?

INF.: - É tiara.

INQ.: - Tiara.

INF.: - No meu tempo, era travessa que se usava e agora é tiara.

INQ.: - Humhum, mudou muito a fala aqui?

INF.: - Pra mim sim, tem as pessoas da minha idade que têm um vocabulário que era daquele tempo, né?

(Porto Alegre, Mulher, Faixa Etária 1, Nível Universitário)

Como é possível visualizar, a identidade social de faixa etária é revelada por meio do uso da denominação travessa. Isso sugere que a identidade social de faixa etária constróise pela revelação de que no passado a informante reconhece um item lexical diferente, caracterizado por travessa, como mostra o exemplo, vinculado a uma fase anterior de sua vida.

\section{CONSIDERAÇÕES FINAIS}

O corpus do Projeto ALiB contempla a documentação da diversidade lexical do português falado na Bahia, que tem contribuições a dar na análise de variantes lexicais, e da Geolinguística Pluridimensional em que o registro segue os parâmetros espaciais e sociais. Em particular, no que diz respeito às denominações que recebem as seis perguntas que compõem o questionário semântico-lexical referente ao campo vestuário e acessórios, podem-se fazer algumas considerações preliminares:

a) as designações enfocadas representam uma variação que possibilita a visualização da diversidade lexical e geolinguística do português falado no Brasil;

b) os dados analisados refletem uma prática de significação do mundo, constituindo e construindo o mundo em significado que possibilita a visualização da construção, manutenção e projeção da identidade social de faixa etária;

c) a temática da comparação passado $\mathrm{X}$ presente está na linguagem da maioria dos informantes de faixa etária mais avançada, evidenciando-se na seleção lexical desses informantes como demonstram os itens porta-seio, corpete, ceroula, calcola, carmim, ruge, biliro e travessa; 
d) a seleção entre as denominações ruge e blush está mais relacionada ao caráter diageracional, porém também está condicionada ao aspecto diassexual como demonstraram os dados apresentados.

O trabalho procurou mostrar como as lexias trazem, na fala dos informantes, as marcas do contexto em que se encontram inseridas, fornecendo subsídios para o registro da diversidade da língua portuguesa e da identidade social de faixa etária.

\section{REFERÊNCIAS}

CARDOSO, Suzana Alice Marcelino. Geolinguística: ampliando fronteiras para o conhecimento do português do Brasil. In: RAZKY, Abdelhak; OLIVEIRA, Marilúcia Barros de; LIMA, Alcides Fernandes de. Estudos geossociolinguisticos do português brasileiro. Campinas: Pontes Editores, 2017, p. 119-135.

CARDOSO, Suzana. et al. Atlas linguistico do Brasil. v. 2. Londrina: Eduel, 2014.

COMITÊ NACIONAL DO PROJETO ALiB: Atlas lingüistico do Brasil. Questionários. Londrina: UEL, 2001.

FAIRCLOUGH, Norman. Discurso e mudanca social. Brasília: Editora Universidade de Brasília, 2001.

HOFFNAGEL, Judith Chambliss. A emergência de identidades na atividade discursiva falada e escrita. In: MOURA, Denilda. Os múltiplos usos da lingua. Maceió: [s.n.], 1999, p. 80-91.

OCHS, Elionor. Linguistic resources for socializaing humanity. In: GUMPERZ, John; LEVINSON, Stephen. Retbinking linguistic relativity. Cambridge: Cambridge University Press, 1993, p. 407-437.

PAIM, Marcela Moura Torres. A emergência de identidade social de faixa etária e variação: o que revelam os dados do Projeto Atlas Linguístico do Brasil (Projeto ALiB). In: MOTA, Jacyra Andrade; PAIM, Marcela Moura Torres; RIBEIRO, Silvana Soares Costa. Documentos 5: Projeto Atlas Linguístico do Brasil, avaliação e perspectivas. Salvador: Quarteto, 2015, p. 245-253.

PRETI, Dino. A linguagem dos idosos. São Paulo: Contexto, 1991.

SANTOS, Irenilde Pereira dos. A variação lexical em atlas linguísticos paulistas: considerações em torno de "chuva". In: SILEL, 2011, Uberlândia. Anais do SILEL. Uberlândia: EDUFU, 2011, p. 1-12.

Recebido em: 28/02/2019

Aprovado em: 07/06/2019

Publicado em: 28/09/2019 